\title{
Preface to the special issue NODYCON 2021, Second International Nonlinear Dynamics Conference, Feb. 16-19, 2021
}

\author{
Muhammad Hajj · Li-Qun Chen • YangQuan Chen (D) Claude H. Lamarque • \\ Sotirios Natsiavas · Hiroshi Yabuno
}

Received: 11 January 2022 / Accepted: 12 January 2022 / Published online: 25 January 2022

(C) The Author(s), under exclusive licence to Springer Nature B.V. 2022

This Special Issue is a collection of some invited contributions presented at the Second International Nonlinear Dynamics Conference (NODYCON 2021, February 16-19, 2021). NODYCON was launched in 2019 as a biennial conference to foster the tradition of the conference series originally established by Prof. Ali H. Nayfeh in 1986 at Virginia Tech, Blacksburg, as the Nonlinear Vibrations, Stability and Dynamics of Structures Conference. With the passing in 2017 of

M. Hajj ( $\square)$

Stevens Institute of Technology, Hoboken, USA

e-mail: mhajj@stevens.edu

L.-Q. Chen

Shangai University, Shanghai, China

e-mail: lqchen@shu.edu.cn

Y. Chen

University of California, Merced, USA

e-mail: ychen53@ucmerced.edu

URL: http://mwchatornics.ucmerced.edu

C. H. Lamarque

ENTPE, Lyon, France

e-mail: Claude-Henri.LAMARQUE@entpe.fr

\section{S. Natsiavas}

Aristotle University, Thessaloniki, Greece

e-mail: natsiava@auth.gr

H. Yabuno

University of Tsukuba, Tsukuba, Japan

e-mail: yabuno@esys.tsukuba.ac.jp
Prof. Nayfeh, NODYCON 2019 was also organized as a collective tribute to Prof. Nayfeh. NODYCON 2019 received an extraordinary response from the community with 408 abstracts (out of 450 submissions) and 400 participants from 68 countries. After the successful launch, NODYCON 2021 was hosted as a virtual (online) conference given the COVID-19 pandemic uncertainties and restrictions. The NODYCON 2021 online conference featured 442 oral presentations covering recent advances in nonlinear dynamics, including new frontiers and challenges.

The authors of a selection of approximately 60 papers were invited to submit their work to this Special Issue. After a rigorous review process, 19 papers were accepted. These papers are grouped according to four major themes:

- Concepts and methods in nonlinear dynamics

- Nonlinear dynamics of mechanical and structural systems

- Nonlinear dynamics and control

- Recent trends in nonlinear dynamics

The first topical area titled Concepts and methods in nonlinear dynamics includes articles concerning the computation of invariant manifolds in high-dimensional finite element models [1], the computation of the basins of attraction of multi-stable dynamical systems [2], reduced-order models for vertical sloshing employing neural networks [3], the problem of continuous representations of piecewise-smooth 
nonlinear systems [4], and analytical approaches to nonlinear singular traveling waves in compressible thermo-hyperelastic cylindrical shells [5].

Articles on the fundamental problem of slippingrolling transitions of a body with two contact points [6], a base-isolated beam under turbulent wind flow [7], analysis of cable-stayed bridges accounting for support stiffness [8], the response of continuous wingbased systems [9] are included in the context of Nonlinear dynamics of mechanical and structural systems.

Articles in the context of Nonlinear dynamics and control include grazing-induced multi-stable responses in impacting systems via time-delayed feedback control [10], position control of an elastic arm with delay-induced bifurcations [11], nonlinear control of an absorption refrigeration system [12], vibration transmission suppression in coupled systems with an inerter-based nonlinear joint [13], tuned inerter dampers [14], and vibration isolation [15].

Recent trends in nonlinear dynamics is a collection of emerging topics tackling parametric resonance and pattern selection in MEMS [16], the effect of uncertainties and noise on the response of microcantilevers [17], enhanced sensitivity of measurements by virtually coupling a resonator with a virtual resonator [18], highly tunable vibration isolation devices exploiting negative stiffness and shape memory material hysteresis [19].

We wish to thank all the authors for their hard work and enthusiasm. We hope that readers will benefit from the diverse collection of papers in this SI and that these papers will inspire new ideas and exciting developments.

Guest Editors of the Special Issue.

Muhammad Hajj (Stevens Institute of Technology, USA).

Li-Qun Chen (Shangai University, China).

YangQuan Chen (University of California, Merced, USA).

Claude H. Lamarque (ENTPE Lyon, France).

Sotirios Natsiavas (Aristotle University, Thessaloniki, Greece).

Hiroshi Yabuno (University of Tsukuba, Japan).

\section{References}

\section{Concepts and methods in nonlinear dynamics}

1. Jain, S., Haller, G.: How to compute invariant manifolds and their reduced dynamics in high-dimensional finite element models. Nonlinear Dyn (2021). https://doi.org/10.1007/ s11071-021-06957-4

2. Stender, M., Hoffmann, N.: bSTAB: an open-source software for computing the basin stability of multi-stable dynamical systems. Nonlinear Dyn. (2021). https://doi.org/10. 1007/s11071-021-06786-5

3. Pizzoli, M., Saltari, F., Mastroddi, F., Martinez-Carrascal, J., González-Gutiérrez, L.M.: Nonlinear reduced-order model for vertical sloshing by employing neural networks. Nonlinear Dyn. (2021). https://doi.org/10.1007/s11071021-06668-w

4. Saunders, B.E., Vasconcellos, R., Kuether, R.J., Abdelkefi, A.: Insights on the continuous representations of piecewisesmooth nonlinear systems: limits of applicability and effectiveness. Nonlinear Dyn. (2021). https://doi.org/10. 1007/s11071-021-06436-w

5. Wang, R., Ding, H., Yuan, X., Lv, N., Chen, L.: Nonlinear singular traveling waves in a slightly compressible thermohyperelastic cylindrical shell. Nonlinear Dyn. (2021). https://doi.org/10.1007/s11071-021-06394-3

\section{Nonlinear dynamics of mechanical and structural systems}

6. Antali, M., Stepan, G.: Slipping-rolling transitions of a body with two contact points. Nonlinear Dyn. (2021). https://doi. org/10.1007/s11071-021-06538-5

7. Di Nino, S., Luongo, A.: Nonlinear dynamics of a baseisolated beam under turbulent wind flow. Nonlinear Dyn. (2021). https://doi.org/10.1007/s11071-021-06412-4

8. Kang, H., Su, X., Pi, Z.: Planar nonlinear dynamic analysis of cable-stayed bridge considering support stiffness. Nonlinear Dyn. (2021). https://doi.org/10.1007/s11071-02106381-8

9. Yossri, W., Bouma, A., Ayed, S.B., Vasconcellos, R., Abdelkefi, A.: Insights on the unsteadiness and stall effects on the characteristics and responses of continuous wingbased systems. Nonlinear Dyn. (2021). https://doi.org/10. 1007/s11071-021-06508-x

\section{Nonlinear dynamics and control}

10. Zhang, Z., Chávez, J.P., Sieber, J., Liu, Y.: Controlling grazing-induced multistability in a piecewise-smooth impacting system via the time-delayed feedback control. Nonlinear Dyn. (2021). https://doi.org/10.1007/s11071021-06511-2 
11. Szaksz, B., Stepan, G.: Delay-induced bifurcations in collocated position control of an elastic arm. Nonlinear Dyn. (2021). https://doi.org/10.1007/s11071-021-06812-6

12. Dong, N., Lv, W., Zhu, S., Gao, Z.K., Grebogi, C.: Modelfree adaptive nonlinear control of the absorption refrigeration system. Nonlinear Dyn. (2021). https://doi.org/10. 1007/s11071-021-06964-5

13. Dong, Z., Shi, B., Yang, J., Li, T.: Suppression of vibration transmission in coupled systems with an inerter-based nonlinear joint. Nonlinear Dyn. (2021). https://doi.org/10. 1007/s11071-021-06847-9

14. Shi, B., Yang, J., Jiang, J.Z.: Tuning methods for tuned inerter dampers coupled to nonlinear primary systems. Nonlinear Dyn. (2022). https://doi.org/10.1007/s11071021-07112-9

15. Niu, M.Q., Chen, L.Q.: Nonlinear vibration isolation via a compliant mechanism and wire ropes. Nonlinear Dyn. (2021). https://doi.org/10.1007/s11071-021-06588-9

\section{Recent trends in nonlinear dynamics}

16. Dick, N., Krylov, S.: Parametric resonance and pattern selection in an array of microcantilevers interacting through fringing electrostatic fields. Nonlinear Dyn. (2021). https:// doi.org/10.1007/s11071-021-06755-y

17. Benedetti, K.C., Gonçalves, P.B.: Nonlinear response of an imperfect microcantilever static and dynamically actuated considering uncertainties and noise. Nonlinear Dyn. (2021). https://doi.org/10.1007/s11071-021-06600-2

18. Uemori, M., Yabuno, H., Ymamamoto, Y., Matsumoto, S.: Highly sensitive measurements of perturbations in stiffness of a resonator by virtual coupling with a virtual resonator. Nonlinear Dyn. (2021). https://doi.org/10.1007/s11071021-06790-9

19. Salvatore, A., Carboni, B., Lacarbonara, W.: Nonlinear dynamic response of an isolation system with superelastic hysteresis and negative stiffness. Nonlinear Dyn. (2021). https://doi.org/10.1007/s11071-021-06666-y

Publisher's Note Springer Nature remains neutral with regard to jurisdictional claims in published maps and institutional affiliations. 